08

\title{
Термоавтоэлектронная эмиссия из квантовых точек антимонида индия
}

\section{() В.Ф. Кабанов, А.И. Михайлов, М.В. Гавриков Ф}

Саратовский национальный исследовательский государственный университет им. Н.Г. Чернышевского, Саратов, Россия ฯE-mail: maks.gavrikov.96@gmail.com

Поступило в Редакцию 18 декабря 2020г.

В окончательной редакции 29 декабря 2020 г.

Принято к публикации 25 января 2021 г.

\begin{abstract}
Выявлены и проанализированы особенности механизма автоэлектронной эмиссии в системе зонд туннельного микроскопа-квантовая точка антимонида индия в температурном диапазоне $23-150^{\circ} \mathrm{C}$. Анализ туннельных вольт-амперных характеристик позволил сделать вывод о различных механизмах переноса электронов из металлического зонда туннельного микроскопа и полевой эмиссии электронов через дискретные энергетические уровни квантовой точки антимонида индия при различных температурах.
\end{abstract}

Ключевые слова: квантовые точки, антимонид индия, автоэлектронная эмиссия, туннельные вольтамперные характеристики.

DOI: 10.21883/PJTF.2021.08.50854.18662

Интерес к исследованиям автоэлектронной эмиссии вызван развитием нано- и микроэлектроники. В условиях реальной работы электронных и оптоэлектронных устройств и приборов с квантово-размерными объектами (ямами и точками) процессы автоэлектронной эмиссии проходят совместно с тепловыми. Термоавтоэлектронная эмиссия определяется и процессами туннелирования, и процессами их теплового возбуждения. При некоторой температуре $T>0^{\circ} \mathrm{C}$ часть электронов находится на уровнях энергии больше $\varepsilon=(3 / 2) k T$ (возбужденные электроны). Для возбужденных электронов потенциальный барьер становится ниже, что увеличивает коэффициент их прохождения через барьер.

Одними из наиболее потенциально востребованных с точки зрения уникальных свойств и перспективы практических приложений [1] являются антимонид индия и структуры с квантовыми точками на его основе.

В настоящей работе проведены исследования автоэлектронной эмиссии электронов в системе зонд туннельного микроскопа-квантовые точки (КТ) антимонида индия при различных температурах.

Коллоидный синтез квантовых точек $\mathrm{InSb}$ проводился согласно методике, описанной в [2,3].

Слои с KT InSb были нанесены на стеклянные подложки с проводящим слоем оксида индия-олова (ITO) и исследованы с помощью методов сканирующей туннельной микроскопии и просвечивающей электронной микроскопии (ПЭМ).

Для понимания и интерпретаций процессов токопереноса в исследуемых образцах привлекались модельные представления туннелирования электронов через дискретные уровни квантово-размерного объекта в структуре [4-6]. Типичное ПЭМ-изображение исследуемых наночастиц InSb представлено на рис. 1. Для даль- нейшего анализа привлекалась модель представления наночастицы как квантовой точки.

Важным для понимания электронных процессов в рассматриваемых КТ, а также эффекта туннелирования электронов через уровни КТ является анализ модельных представлений термоэлектронной эмиссии из зонда туннельного микроскопа через КТ в металлический контакт ITO (отрицательное смещение на зонде) и обратно в зонд (положительное смещение на зонде). Выбор модели термополевой эмиссии в качестве основного в рассматриваемой системе механизма переноса электронов обусловлен тем, что расстояние между КТ и зондом вы-

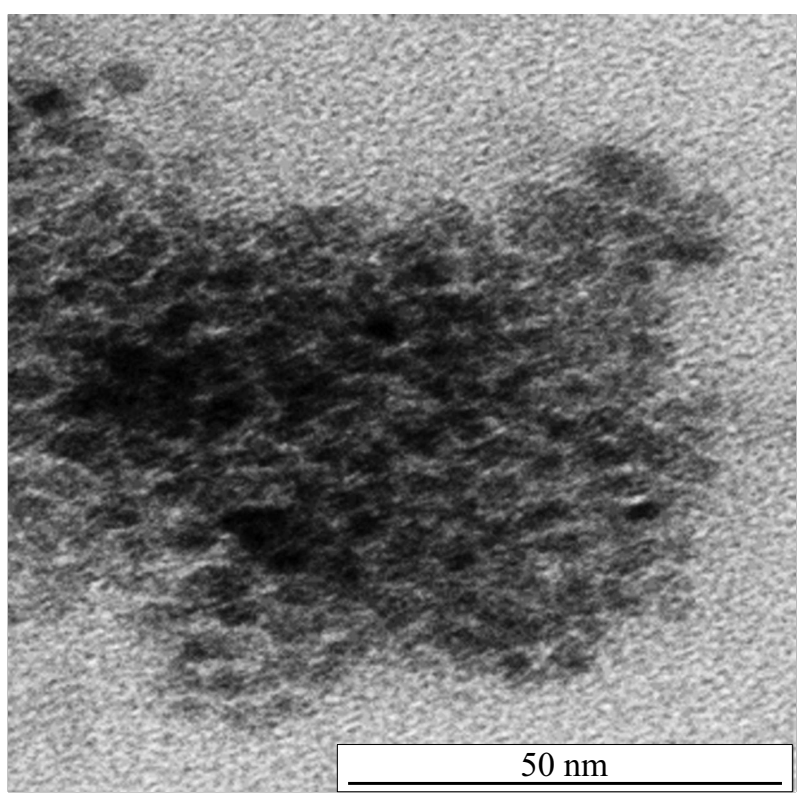

Рис. 1. Типичное ПЭМ-изображение КТ InSb. 


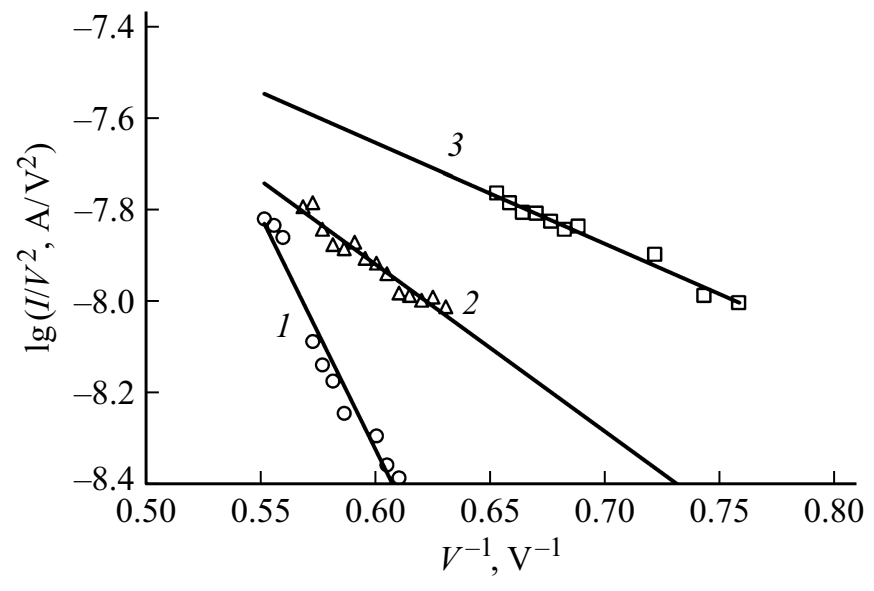

Рис. 2. Вольт-амперные характеристики КТ InSb (положительное смещение на образце) в координатах $\lg \left(I / V^{2}\right)-V^{-1} . T,{ }^{\circ} \mathrm{C}$ : $1-23,2-90,3-150$.

биралось порядка $1 \mathrm{~nm}$ и напряженность электрического поля по оценке составляла величину более $5 \cdot 10^{6} \mathrm{~V} / \mathrm{cm}$.

Степень прозрачности потенциального барьера определяет вероятность туннелирования электрона, попадающего на барьер, и соответственно значения плотности тока термоэлектронной эмиссии. Вероятность туннелирования электрона сквозь потенциальный барьер определяется по известной формуле [7]:

$$
W(\varepsilon) \approx \exp \left(-\frac{4 \pi}{\hbar} \int_{x_{1}}^{x_{2}} \sqrt{2 m_{0}(U(x)-\varepsilon)} d x\right),
$$

где $U(x)$ и $\varepsilon-$ соответственно потенциальная и полная энергия электрона; $x_{1}$ и $x_{2}$ являются решениями уравнения $\varepsilon=U(x)$ и определяют энергетический интервал, в котором происходят обозначенные процессы.

Вероятность туннелирования $W(\varepsilon)$ увеличивается при повышении энергии $\varepsilon$ электрона, например, с ростом общей температуры системы. Это должно сказываться на эффективной высоте барьера и величине туннельного потока электронов из зонда туннельного микроскопа через дискретные уровни КТ в металлический контакт (ITO). При обратной полярности приложенного напряжения полевая эмиссия электронов осуществляется через уровни КТ (при соответствующем смещении $q V=\varepsilon_{i}$, где $\varepsilon_{i}-$ i-й дискретный энергетический уровень КТ [4], $q$ - модуль заряда электрона, $V$ напряжение). Величина $\varepsilon_{1}$ первого уровня КT $\mathrm{InSb}$ (через который в основном и реализуется механизм туннелирования) при характерных размерах порядка $8 \mathrm{~nm}$ (рис. 1) составляет величину около $1.0 \mathrm{eV}$. В этом случае увеличение температуры на несколько десятков градусов от комнатной соответствует изменению энергии не более чем на $0.01 \mathrm{eV}$, что практически не должно сказываться на механизме полевой эмиссии электронов через уровни КТ в зонд микроскопа. Величина эффективного энергетического барьера для электронов, эмитированных из ITO, определяется приложенным к структуре напряжением и практически не зависит от температуры (вклад менее 1\%).

В работе проводились измерения туннельных вольт-амперных характеристик (BАХ) в системе зонд микроскопа-воздушный зазор (туннельно-тонкий порядка $1 \mathrm{~nm}$ )-КТ (характерный размер порядка 8-10 nm)-ITO (металлический электрод) при температурах 23,90 и $150^{\circ} \mathrm{C}$.

Результаты измерений при положительном смещении на образце (эмиссия электронов из зонда) представлены на рис. 2.

Эти экспериментальные данные показывают, что с ростом температуры возрастает величина тока автоэлектронной эмиссии и, что существенно важно, изменяется наклон характеристики в координатах Фаулера-Нордгейма. Последнее свидетельствует об изменении эффективной высоты потенциального барьера и увеличении вероятности туннелирования через барьер, связанного с возрастанием энергии электронов при нагревании системы.

Зависимость плотности тока от напряженности электрического поля (и соответственно приложенного напряжения) при рассмотрении автоэлектронной эмиссии из полупроводника [8] может быть представлена следующим образом:

$$
j_{s} \sim \exp \left(-\frac{\theta}{E}\right)
$$

где $\theta-$ значение функции Нордгейма, $E-$ напряженность электрического поля. Локальную напряженность электрического поля в одномерном приближении можно оценить по формуле $E=V / d$, где $V$ - приложенное напряжение, $d$ - расстояние между КТ и зондом.

Для подтверждения описанного выше механизма автоэлектронной эмиссии были проведены исследования туннельных ВАХ при отрицательном смещении на образце. Результаты представлены на рис. 3.

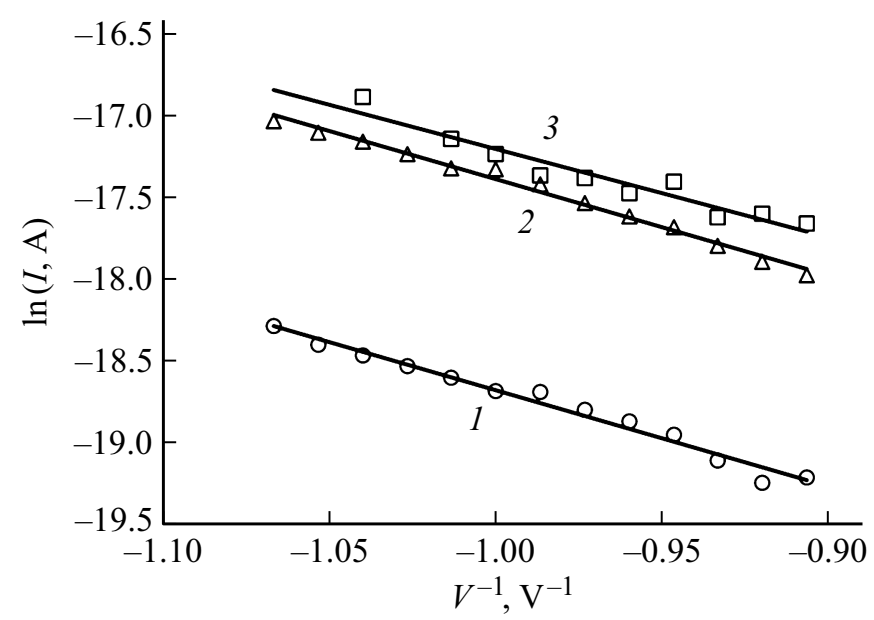

Рис. 3. Вольт-амперные характеристики КТ InSb (отрицательное смещение на образце) в координатах $\ln I-V^{-1} . T,{ }^{\circ} \mathrm{C}$ : $1-23,2-90,3-150$. 
Эти экспериментальные результаты показывают довольно хорошую линейность зависимостей в рассматриваемом диапазоне напряжений в указанных координатах в соответствии с (2). Сохранение угла наклона зависимостей при различных температурах позволяет считать, что механизм наблюдавшегося тока термоавтоэлектронной эмиссии через дискретные энергетические уровни квантовой точки может быть удовлетворительно описан в соответствии с подходами, сформулированными в настоящей работе. Проведенная оценка величины функции Нордгейма $\theta$, учитывающей понижение потенциального барьера, для KT InSb дает значение порядка $(0.16-0.17) \cdot 10^{-1}$, что хорошо коррелирует с результатами [2].

В настоящей работе на основе экспериментально полученных туннельных ВАХ проведено исследование и получена теоретическая оценка некоторых параметров, характеризующих физический механизм термоэлектронной эмиссии в системе зонд туннельного микроскопа-квантовая точка антимонида индия при различных температурах. Наблюдавшееся изменение наклона BAX в координатах Фаулера-Нордгейма (эмиссия электронов из зонда) свидетельствует об изменении эффективной высоты потенциального барьера, связанного с повышением энергии электронов при нагревании системы. Линейность ВАX (при эмиссии электронов из КТ) и сохранение угла наклона при различных температурах позволяют считать, что механизм наблюдавшегося тока термоавтоэлектронной эмиссии через квантовую точку антимонида индия адекватно описывается теорией Моргулиса-Стрэттона в диапазоне значений напряженности электрического поля, соответствующем условиям экспериментов.

\section{Финансирование работы}

Исследование выполнено при финансовой поддержке Российского фонда фундаментальных исследований в рамках научных проектов № 19-07-00087 и 19-07-00086.

\section{Конфликт интересов}

Авторы заявляют, что у них нет конфликта интересов.

\section{Список литературы}

[1] А.И. Михайлов, В.Ф. Кабанов, Н.Д. Жуков, Письма в ЖТФ, 41 (12), 8 (2015). [Пер. версия: 10.1134/S1063785015060267].

[2] W. Liu, A.Y. Chang, R.D. Schaller, D.V. Talapin, J. Am. Chem. Soc., 134 (50), 20258 (2012). DOI: 10.1021/ja309821j

[3] А.И. Михайлов, В.Ф. Кабанов, М.В. Гавриков, Письма в ЖТФ, 46 (7), 36 (2020).

DOI: 10.21883/PJTF.2020.07.49218.18145 [Пер. версия: $10.1134 / \mathrm{S} 1063785020040100]$

[4] A.I. Mikhailov, V.F. Kabanov, E.G. Glukhovskoy, M.I. Shishkin, M.V. Gavrikov, Nanosystems: Physics, Chemistry, Mathematics, 9 (4), 464 (2018).

DOI: $10.17586 / 2220-8054-2018-9-4-464-467$
[5] А.И. Михайлов, В.Ф. Кабанов, И.А. Горбачев, Е.Г. Глуховской, ФТП, 52 (6), 603 (2018).

DOI: 10.21883/FTP.2018.06.45923.8443 [Пер. версия: 10.1134/S1063782618060155].

[6] А.И. Михайлов, В.Ф. Кабанов, И.А. Горбачев, А.В. Казак, Н.В. Усольцева, Е.Г. Глуховской, Изв. РАН. Сер. физ., 81 (12), 1668 (2017).

[7] Л.Л. Гольдин, Г.И. Новикова, Квантовая физика. Вводный курс (Ин-т компьютерных исследований, М., 2002).

[8] Н.В. Егоров, Е.П. Шешин, Автоэлектронная эмиссия. Принципы и приборы (Интеллект, Долгопрудный, 2011). 